\title{
Propaganda de Medicamentos no Brasil: o que mudou?
}

\author{
Drug Advertising in Brazil: what has changed? \\ Publicidad de medicamentos em Brasil: ¿qué ha cambiado?
}

\author{
Julia dos Santos Coli de Araujo \\ ORCID: https://orcid.org/0000-0001-9915-3004 \\ Universidade Federal do Estado do Rio de Janeiro, Brasil \\ E-mail: juliacoliaraujo@gmail.com \\ Michele Feitoza-Silva \\ ORCID: https://orcid.org/0000-0003-2717-7239 \\ Fundação Oswaldo Cruz, Brasil \\ E-mail: michele.feitoza@fiocruz.br \\ Bianca Ramos Marins Silva \\ ORCID: https://orcid.org/0000-0002-2664-9794 \\ Universidade Federal do Estado do Rio de Janeiro, Brasil \\ E-mail: bianca.silva@unirio.br
}

\begin{abstract}
Resumo
A indústria farmacêutica utiliza a propaganda de medicamentos como principal instrumento para influenciar prescritores e promover a venda. A fim de orientar este mercado, a Regulação Sanitária brasileira iniciou-se em 1976 com a criação da Lei de Vigilância Sanitária $n^{\circ}$ 6.360. Os critérios éticos para a propaganda de medicamentos no Brasil estão orientados por normas definidas pela Organização Mundial de Saúde (OMS), em 1988, sendo a base para a elaboração da Resolução da Diretoria Colegiada 96/2008 atualmente vigente. Para entender a atual conjuntura, o presente estudo verificou a legitimidade do conteúdo das peças publicitárias de medicamentos direcionadas ao público usando como norte regulatório as exigências da Agência Nacional de Vigilância Sanitária. Dentre as não conformidades nas propagandas, pode-se destacar que $65 \%$ das peças não possuíam a frase preconizada 'Se persistirem os sintomas, $o$ médico deverá ser consultado'. Os resultados obtidos reiteram a necessidade de constante fiscalização das peças publicitárias, a fim de que os danos à saúde da população sejam mínimos.
\end{abstract}

Palavras-chave: Saúde; Publicidade; Preparações farmacêuticas; Vigilância sanitária.

\begin{abstract}
The pharmaceutical industry takes advantage of the drug propaganda as the main strategy to influence prescribers and promote sales. In order to guide this market, the Brazilian Sanitary Regulation has begun in 1976 by the creation of the Sanitary Surveillance Law $n^{\circ}$ 6360. The ethical parameters for the drug propaganda in Brazil are guided by standards defined by the World Health Organization (WHO) in 1988, which are the basis for the elaboration of the current Directors' Collegiate Resolution (RDC) 96/2008. For the purpose of comprehension of the actual scenario, this study verified the legitimacy of the content of the drug propagandas directed to the public, which uses the requirements of Nacional Agency of Sanitary Surveillance (ANVISA) as guidelines. Among the illegalities, $65 \%$ of the propagandas didn't show the recommended slogan "if the symptoms persist, your doctor may be consulted". The results obtained reaffirm the need of constant supervision of the propagandas in order to reduce the damage to the population health.
\end{abstract}

Keywords: Health; Advertising; Pharmaceutical preparations; Health surveillance.

\section{Resumen}

La industria farmacéutica aprovecha la propaganda de las drogas como principal estrategia para influir en los prescriptores y promover las ventas. Para orientar este mercado, el Reglamento Sanitario Brasileño se inició en 1976 con la creación de la Ley de Vigilancia Sanitaria n ${ }^{\circ}$ 6360. Los parámetros éticos para la propaganda de drogas en Brasil se rigen por estándares definidos por la Organización Mundial de la Salud (OMS) en 1988. , que son la base para la elaboración de la actual Resolución Colegiada de Directores (RDC) 96/2008. Con el propósito de comprender el escenario actual, este estudio verificó la legitimidad del contenido de las propagandas de drogas dirigidas al público, que utiliza como lineamientos los requisitos de la Agencia Nacional de Vigilancia Sanitaria (ANVISA). Entre las ilegalidades, el $65 \%$ de las propagandas no mostraba el lema recomendado "si los síntomas persisten, se puede consultar a su médico". Los resultados obtenidos reafirman la necesidad de una supervisión constante de las propagandas para reducir el daño a la salud de la población.

Palabras clave: Salud; Publicidad; Preparaciones farmacéuticas; Vigilancia sanitaria. 


\section{Introdução}

Historicamente, o marco regulatório das propagandas de medicamentos aconteceu durante o desenvolvimento econômico brasileiro, em 1976, no Governo Geisel. Neste mesmo ano, foi promulgada a Lei da Vigilância Sanitária nº . 6360, em 23 de setembro.

A referida Lei determinava regras sobre a vigilância sanitária em que ficam sujeitos os medicamentos, as drogas, os insumos farmacêuticos e correlatos, cosméticos, saneantes e outras providências. Estão entre suas competências, a regulação de rotulagem, embalagem, registro, fabricação, matérias-primas, lote, controle de qualidade e pureza. Nessa norma, estão os aspectos introdutórios para legislações posteriores como a proibição de propaganda de medicamentos sob prescrição para o consumidor, dentre outras, de forma consolidada é a principal referência em Vigilância Sanitária no Brasil (Lei nº 6.360, 2000).

Após um ano é publicada a Lei n. 6.437/1977, caracterizando como infração sanitária a propaganda de medicamentos irregulares. Para tal controle, formas de penalidades são estabelecidas e perpetradas através de advertências, suspensão da propaganda e multas (Abdalla \& Castilho, 2017).

O Código de Defesa do Consumidor, Lei nº 8078/90, além de tratar sobre o mercado de produtos e serviços, regula a publicidade ao estabelecer um limiar ético para essas atividades. Torna-se a primeira medida legislativa, no Brasil, abordando a propaganda de insumos, sendo promulgada no Governo Collor. O objetivo desta Lei é garantir o direito do consumidor atribuindo ao produtor, a responsabilidade da produção, do serviço e da qualidade (Lei n 8.078, 1990). Apesar do Código não tratar diretamente de aspectos de saúde, a publicação infere e reforça a importância da regulação de insumos que possam interferir na saúde pública. Ademais, a Lei n. 9.294/1996 é concretizada pelo Decreto n. 2.018/1996 e impõe que a frase "Ao persistirem os sintomas, o médico deverá ser consultado” seja inclusa na propaganda (Decreto Federal n² 2.018, 1996).

Em 1998, pela Lei 9.782, houve a criação da Agência Nacional de Vigilância Sanitária (Anvisa), órgão de caráter autônomo que tem como uma de suas atribuições, entre outras, normatizar a propaganda de medicamentos (Lei $\left.\mathrm{n}^{\circ} 9.782,1999\right)$.

Respaldada pela Anvisa, a Resolução da Diretoria Colegiada (RDC) 102/2000 é criada para instituir a regulação sanitária específica da propaganda de medicamentos ( $\left.\operatorname{RDC~}^{\circ} 102,2000\right)$. Foi criado, em 2002, um projeto em parceria com universidades públicas denominado Monitoração da Propaganda e Publicidade de Medicamentos, visando monitorar a legislação vigente (Monitoração de Propaganda, 2005). Nessa perspectiva, foi promulgada a RDC nº. 96/2008 da Anvisa que permite a veiculação da propaganda de medicamentos, desde que as informações contidas nestas sejam compatíveis com as do registro. Nesta, também há proibição da prática de propaganda enganosa e abusiva ( $\left.\operatorname{RDC~n}^{\circ} 96,2008\right)$.

O objetivo primordial da propaganda é estimular o consumo e uma das principais estratégias da indústria farmacêutica é oferecer a falsa sensação de autonomia ao consumidor. Esta falácia decorrente das propagandas, apresenta um produto simbolicamente valorizado que deixa de ser apenas um produto com potencial risco de uso e passa a ser a solução imediata para a saúde (Monitoração de Propaganda, 2005).

Diante da lógica capitalista em que estamos inseridos, podemos vislumbrar uma inversão de valores com estímulo crescente ao consumo de produtos que nem sempre são necessários. Ainda assim, a terapia medicamentosa contribui para a manutenção do bem-estar e prolongamento da vida. Nesse sentido, tem sido estabelecida uma cultura irracional de medicalização que aliada à propaganda sem regulação, pode trazer danos graves à saúde da população (Sato, 2002). Nascimento (2005) descreve sobre estas tendências:

Diretamente junto à população consumidora de produtos farmacêuticos, a propaganda é utilizada como mais um instrumento de reforço da, já existente, cultura da medicalização. Este fator atua fortemente associado à ideologia de consumo - disseminada na sociedade - como caminho mais rápido de se alcançar saúde, bem-estar e, em última instância, a felicidade. 
De acordo com a OMS (2010) citada por Trevisol DJ, Ferreira MBC e Karnopp ZMP (2010), em média 50\% dos medicamentos serão prescritos, dispensados ou usados inadequadamente, 50 a 70\% das consultas geram prescrição médica, porém até 50\% dos pacientes administram de forma incorreta. Nessa perspectiva e, de acordo com o Sistema Nacional de Informações Tóxico Farmacológicas da Fiocruz, os medicamentos estão em primeiro lugar entre os principais agentes responsáveis por intoxicação humana no Brasil (Casos registrados de intoxicação humana, 2008) São 65 casos diários de intoxicação por medicamento: um a cada 24 minutos oficialmente registrados apenas no Sistema Único de Saúde (SUS) (Casos de intoxicação humana, 2008). Dados mais recentes de 2017, mostram que do total de 20637 intoxicações as principais causas relacionadas são: automedicação (397), uso terapêutico (953 casos), erro de administração (1392 casos), acidente individual (5051 casos) e tentativas de suicídio (9983 casos) (Casos de intoxicação humana por agente tóxico, 2017). Andrade et al. (2020) identificaram que entre 2010-2017, no Brasil, foram notificados 565.271 casos de intoxicação por agente, sendo 298.976 (52.8\%) casos por medicamentos. Além da intoxicação medicamentosa, têm-se o risco de resistência microbiana associado ao uso impróprio dos Antibióticos (Costa \& Silva, 2017).

No estudo de Barros e Joany (2002) foi evidenciado que os anúncios da indústria farmacêutica para público especializado omitiam, em sua grande maioria, dados importantes, tais como reações adversas, contraindicações e interações, e ainda dispunham de informações de caráter tendencioso (Barros \& Joany, 2002).

Esta é a importância de avaliar propagandas de medicamentos e a veracidade das informações contidas nestas, uma vez que estão relacionadas a tipos diferentes de substâncias, sob diversas perspectivas de mecanismos de ação. Podem tratar, potencializar outras drogas e acarretar danos a partir do uso indevido.

A regulamentação de leis que balizam a publicidade de medicamentos funciona como ações protetivas à saúde pública. Assim, as resoluções sanitárias garantem critérios seguros para a comercialização e uso. De acordo com Araujo et al (2012), a Resolução da Diretoria Colegiada (RDC) 96/2008, tem como intenção regulamentar critérios sanitários que garantam informações seguras e fundamentadas de acordo com critérios técnico-científicos, capazes de priorizar o direito à saúde dos indivíduos, sem cercear a crescimento da indústria de medicamentos (Araujo, Bochner \& Nascimento, 2012). Corroborando, Fagundes, Soares e Diniz (2007) elucidam que o Estado se torna inteiramente responsável e deve intervir na saúde pública para que se evite agravos à saúde da população. Maia et al. (2019) estabelece que os indicadores em saúde devem ser prioridade, visto que a qualidade dos dados é dependente da precisão destas informações nos sistemas de notificação, facilitando planejamento, implementação e medidas para prevenção de agravos.

Dessa forma, o objetivo deste estudo foi avaliar a conformidade de peças publicitárias farmacêuticas frente a RDC n. 96 de 17 de dezembro de 2008.

\section{Metodologia}

Trata-se de um estudo quantitativo-qualitativo, baseado na análise de peças publicitárias, realizado no período de julho de 2017 a agosto de 2018 em ambulatórios de um Hospital Universitário Federal localizado na cidade do Rio de Janeiro, ressaltase ainda que este hospital é referência para doenças infectocontagiosas e foi permitido o acesso em 25 dos 26 ambulatórios. Entretanto, foram coletados materiais em 8 ambulatórios médicos, pois 17 não dispunham de peças publicitárias no momento.

Para direcionamento do arcabouço teórico foi realizado levantamento bibliográfico sobre a temática desenvolvida no estudo, como a propaganda de medicamentos, influência da propaganda de medicamentos, risco à saúde e medicamentos de venda livre. 
Nesse sentido, foram selecionados artigos para subsidiar o estudo sobre as estratégias mercadológicas destinadas ao público prescritor. Neste estudo adotou-se como escopo analítico os critérios balizados nas normas sanitárias, RDC 102/2000 e a RDC 96/2008, ambas da ANVISA, sendo esta última, a vigente.

As peças publicitárias recolhidas foram coletadas e catalogadas por apenas um observador de acordo com os ambulatórios anuentes para participação nesta pesquisa. Adotou-se como critério de catalogação uma numeração alfanumérica e a análise procedeu de acordo com os itens preconizados pela norma sanitária vigente. Para garantir a uniformidade da análise, o conteúdo dos anúncios e a RDC 96/2008 foram comparados pelo mesmo pesquisador.

Para a construção do roteiro analítico aplicado às peças, levou-se em consideração os critérios dispostos na RDC $\mathrm{n}^{\circ}$ 96/2008. O roteiro desenvolvido atendeu aos aspectos regulatórios definidos e categorizados em 3 itens principais requisitos: Requisitos Gerais - composto por 20 parágrafos e/ou artigos que indicam as características gerais da apresentação da propaganda; Requisitos para medicamentos sem exigência de prescrição - composto por 18 parágrafos e/ou artigos e Requisitos para medicamentos de venda sob prescrição - composto por 21 parágrafos e/ou artigos.

As peças publicitárias coletadas foram analisadas de acordo com os aspectos regulatórios preconizados na legislação, a fim de verificar a conformidade ou não às exigências sanitárias definidas pela Anvisa. A análise de adequação da informação se deu de acordo com protocolos utilizados pelo laboratório oficial do Sistema Nacional de Vigilância Sanitária (SNVS), o Instituto Nacional de Controle de Qualidade em Saúde (INCQS). A presença de um item discordante com a legislação vigente torna o produto/material não conforme, a exemplo do estudo com seringas hipodérmicas (Feitoza-Silva et al. 2016). Foram analisados 59 aspectos regulatórios aplicados às propagandas. Para cada aspecto regulatório considera-se: 'sim' referente à concordância da propaganda, ou seja, 'conformidade’ à Resolução e 'não' refere à 'não conformidade' aos requisitos exigidos; assinalando-se com ' $\mathrm{X}$ ' o campo correspondente. Durante a sistematização das peças publicitárias levou-se em consideração a classe terapêutica dos medicamentos anunciados nestas propagandas. Esta estratégia permitiu observar quais são as classes terapêuticas mais divulgadas junto aos profissionais de saúde.

\section{Resultados e Discussão}

Para Nascimento (2010), a RDC 96/2008 manteve fragilidades regulatórias. Pois o consentimento prévio das peças publicitárias antes da publicação e punições mais rígidas em caso de descumprimento da nova RDC, não foram consideradas. Assim sendo, ainda se observa a incidência de intoxicações medicamentosas e o grande volume de propagandas irregulares e acessíveis, demonstrando que as ações da Vigilância Sanitária, àquelas relacionadas ao monitoramento do mercado, devem ter maior rigor regulatório para a real proteção da saúde da população.

Ademais, observa-se que a RDC n 96/2008 aproxima-se às diretrizes definidas pela Organização Mundial de Saúde (OMS) em 1988. Na Conferência de Especialistas sobre Uso Racional de Medicamentos, a OMS apontou que a perspectiva internacional acerca da propaganda de medicamentos contribui para a atualização dos Critérios Éticos para a Promoção de Medicamentos objetivando promover a saúde através de parâmetros éticos viáveis para cada governo de acordo com a legislação e contexto vigente, promover a saúde e fomentar o uso racional (Criterios éticos para lá promocion de medicamentos, 1985).

De acordo com a diretriz da OMS de 1988 toda propaganda que contenha afirmações alusiva a medicamentos deve ser exata, informativa, equilibrada, atualizada, fidedigna e com teor comprobatório. São vetadas as declarações que induzam uma interpretação equivocada, que não possa ser comprovada ou realizar omissão de informações que conduzam à utilização de medicamentos para fins não ponderados. E ainda, a publicidade dirigida a médicos e profissionais da saúde deve ser conciliável com dados científicos publicados sobre o medicamento contendo a identificação essencial: nome do princípio ativo, com denominação comum internacional (DCI); o nome genérico aprovado do medicamento; o nome comercial; nome de excipientes; usos terapêuticos aprovados; forma farmacêutica e posologia; reações adversas ao medicamento; cuidados, contra indicações e 
advertências; interações medicamentosas principais; nome e endereço do fabricante ou distribuidor; e referências (Monitoração de Propaganda, 2005).

No Gráfico 1, de acordo com a classe terapêutica e os itens regulamentados na RDC 96/2008 para os requisitos gerais, conforme o "Art. $8^{\circ}$ É vedado na propaganda ou publicidade de medicamentos: "I - estimular e/ou induzir o uso indiscriminado de medicamentos".

Gráfico 1. Distribuição das não conformidades segundo classe terapêutica.

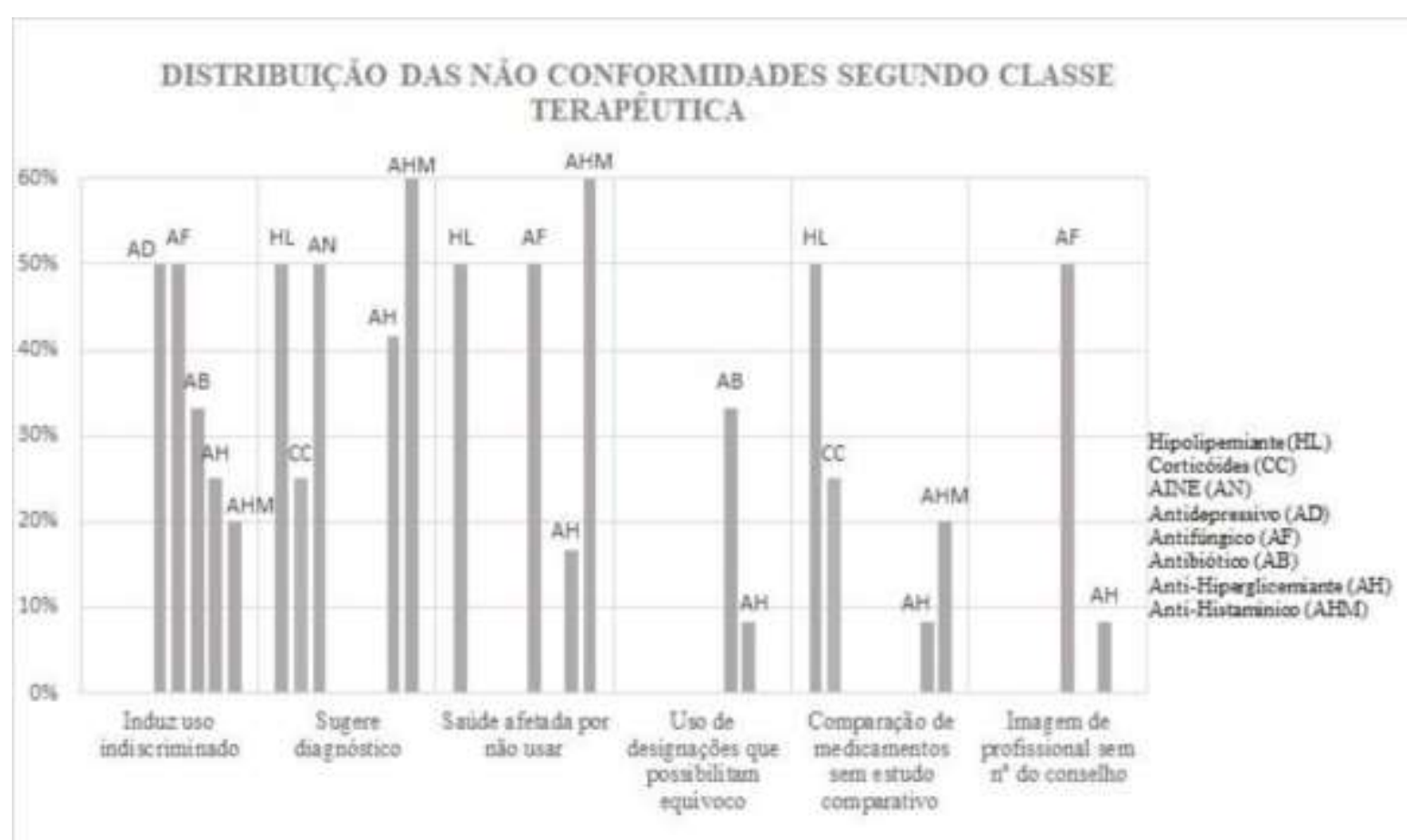

Fonte: Autores.

Em documento publicado pela ANVISA, "Regulamentação da Propaganda de Medicamentos: RDC 96 - Perguntas e Respostas" descreve sendo uso indiscriminado de medicamento, como: o uso de qualquer informação, imagem ou outros argumentos que induzam o uso incorreto, estimulem a administração do medicamento por pessoas de faixas etárias contraindicadas ou que banalizem o uso do medicamento para qualquer situação (RDC n 96 - Perguntas e Respostas, 2017).

No presente estudo, induziram o uso indiscriminado de medicamentos, $50 \%$ dos antidepressivos e antifúngicos, 33,3\% dos antibióticos, $25 \%$ dos anti-hiperglicemiantes e $20 \%$ dos anti-histamínicos. Na propaganda de antidepressivos, foi possível observar o uso de frases como: "sinta-se bem consigo mesmo", "fique bem em qualquer hora do dia", "tenha sempre na bolsa" como foi verificado nos dados desta pesquisa. Isto conota, que a melhoria continuada do estado de saúde do indivíduo deve-se a necessidade do uso do medicamento. Conforme Mastroianni et al (2008), a propaganda farmacêutica se estabelece com a promessa de que o psicofármaco é "libertador" ao oferecer paz de espírito e reequilíbrio psíquico. Estas estratégias mercadológicas são capazes de induzir o consumidor ao uso de medicamentos, sem a devida orientação médica, expondo-o ao risco de efeitos adversos, intoxicação e até morte.

Ainda de acordo com documento publicado pela ANVISA "II - sugerir ou estimular diagnósticos ao público em geral” estabelece que a propaganda pode dizer que é indicado para inflamação, mas não poderá afirmar que pessoas com garganta dolorida e vermelha devem usar o produto (RDC n 96 - Perguntas e Respostas, 2017). Assim, neste estudo, observou-se que o diagnóstico foi sugerido nas propagandas de $60 \%$ dos anti-histamínicos, 50\% dos hipolipemiantes e AINEs, 41,6\% dos anti- 
hiperglicemiantes e $25 \%$ dos corticoides. Nestes, foram identificadas frases que sugeriam o diagnóstico, como: "Diminua seu risco cardiovascular, evite o infarto", "para contraturas e torções musculares", "inimiga do açúcar alto". Klein et al. (2020) agrega com o estudo ao trazer que em $80 \%$ de seus entrevistados já se automedicaram, preponderantemente, com AINEs e antibióticos para tratamento de gripe, dor de garganta e tosse.

Observou-se ainda que foram empregados o imperativo 'tome' ou 'use', 33,3\% dos anti-hiperglicemiantes. E descreveram que a saúde do usuário seria afetada caso não fosse utilizado o medicamento em $60 \%$ dos anti-histamínicos, $50 \%$ dos antifúngicos e hipolipemiantes e 16,6\% dos anti-hiperglicemiantes.

No Art. 30, parágrafo $3^{\circ}$ da RDC 96/2008 é explicitado que: “Os gráficos, tabelas e ilustrações de mecanismos de ação... devem ser verdadeiros, completos, bem como não podem ser apresentados de forma que possibilitem erro ou confusão quanto às características do medicamento através do impacto visual ( $\left(\mathrm{RDC} \mathrm{n}^{\circ} 96,2008\right)$

Neste estudo, 33,3\% dos antibióticos e 8,3\% dos anti-hiperglicemiantes eram de propagandas que usaram de artifícios que possibilitavam interpretação errada da informação com gráficos de difícil leitura pelo pequeno tamanho das letras e dificuldade na leitura de símbolos correspondentes das curvas e legendas, traduzindo-se numa informação possivelmente dúbia e de difícil assimilação.

Os dados revelaram ainda que foram estabelecidas comparações sem balizamentos científicos em $50 \%$ dos hipolipemiantes, $25 \%$ dos corticóides, $20 \%$ dos anti-histamínicos e 8,3\% dos anti-hiperglicemiantes.

No que se refere a utilização (fizeram menção) à imagem de profissional de saúde sem apresentar número do conselho, foi verificada em $50 \%$ das propagandas dos antifúngicos e 8,3\% dos anti-hiperglicemiantes.

Em estudo desenvolvido por Heineck et al. (1998) a partir da análise de 250 peças publicitárias de medicamentos, em $89 \%$ das peças, os dados sobre a posologia e o fabricante eram ausentes. Ademais, $100 \%$ das peças não continham as contraindicações, cuidados e advertências quanto ao uso ${ }^{9}$. Os autores evidenciaram que haviam importantes lacunas no que se refere as informações básicas nos anúncios propagados.

O Gráfico 2 que compara classe terapêutica e os itens preconizados na legislação para medicamentos isentos de prescrição, os resultados mostram que em 50\% dos antidepressivos, 40\% dos anti-histamínicos, 33,3\% dos antibióticos e 25\% dos corticóides e anti-hiperglicemiantes não continham o alerta "se persistirem os sintomas, o médico deverá ser consultado". Esta não observância aos preceitos legais ainda é frequentemente observado na literatura. 
Gráfico 2. Não conformidade da classe terapêutica em relação ao componente isento de prescrição da RDC 96/2008.

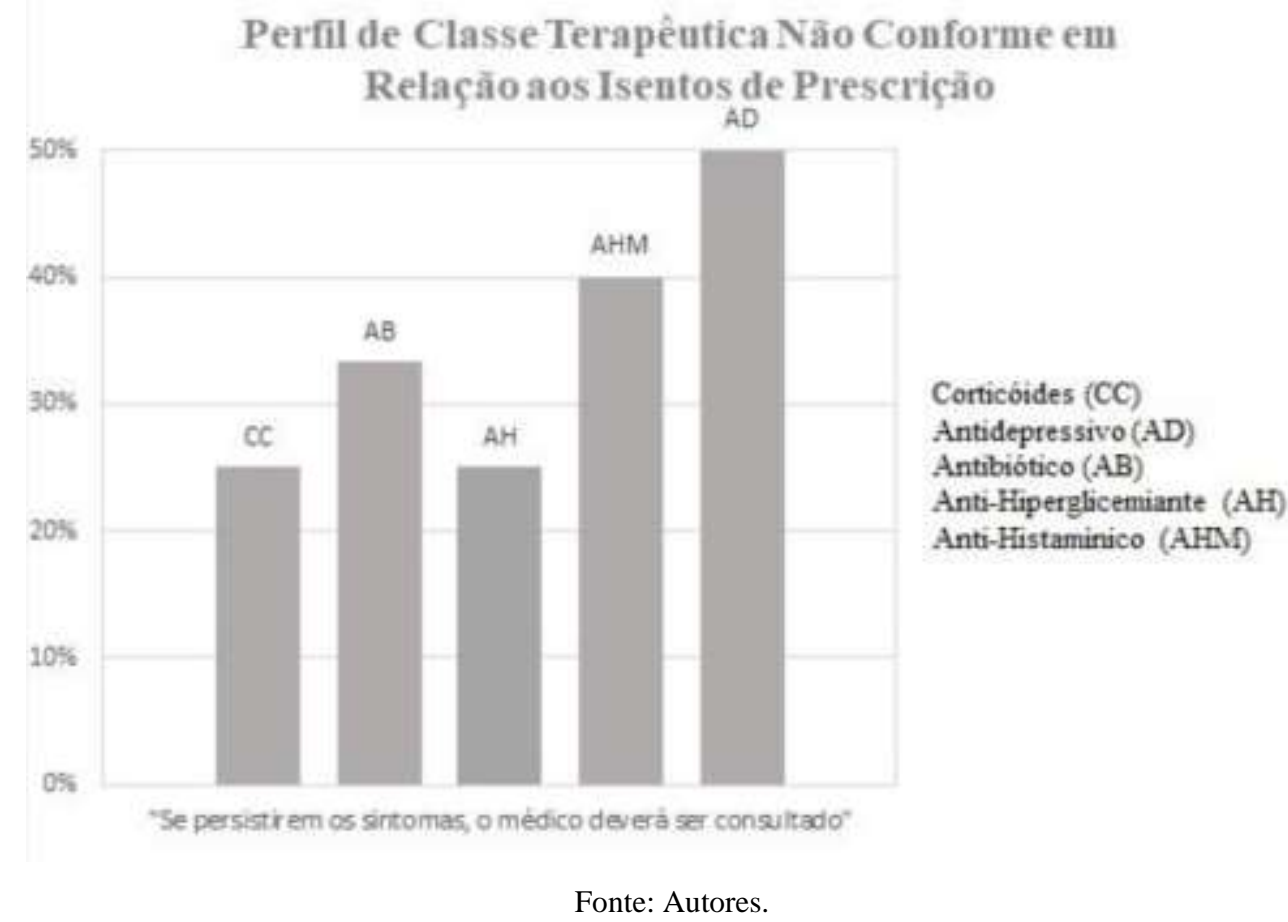

Ao analisarem propagandas de medicamentos encontradas em farmácias comunitárias, um estudo realizado em 2016 revelou que em 45,4\% destas também não incluíam o alerta, sendo contabilizado como um dos pontos da legislação mais infringidos dentre as peças recolhidas (Silva, Rangel \& Castilho, 2018). No estudo de Nascimento (2005), este artigo é descumprido 19 vezes em 100 anúncios. Em concordância com Silva, Rangel e Castilho (2018), a confiabilidade destas propagandas é questionável, pois apresentam diversas irregularidades em relação à Anvisa expondo a população ao risco do uso irracional de medicamentos.

Em um estudo realizado por Villanueva et al (2003), foram analisados periódicos médicos espanhóis de 1997 que continham propagandas de anti-hipertensivos e antilipêmicos. Os resultados foram concordantes aos dados desta pesquisa, pois em $44 \%$ das peças os dados que constavam nas referências não justificavam o apelo promocional, assim como em $18 \%$ eram de estudos e monografias não publicadas e ainda continham declarações não demonstradas pela análise estatística e ausência da relação entre propaganda e o estudo (Villanueva et al. 2003).

Estes fatos revelam não apenas discordância à RDC 96/2008, mas também ao Estatuto da Criança e do Adolescente (ECA), pois 2,3\% dos anti-histamínicos incluíam mensagem não-verbal dirigida a crianças e adolescentes (Estatuto da Criança e do Adolescente, 1990).

No Gráfico 3, há a classe terapêutica e os itens preconizados na legislação para medicamentos sob prescrição. 
Gráfico 3. Não conformidade da classe terapêutica em relação ao componente sob prescrição da RDC 96/2008.

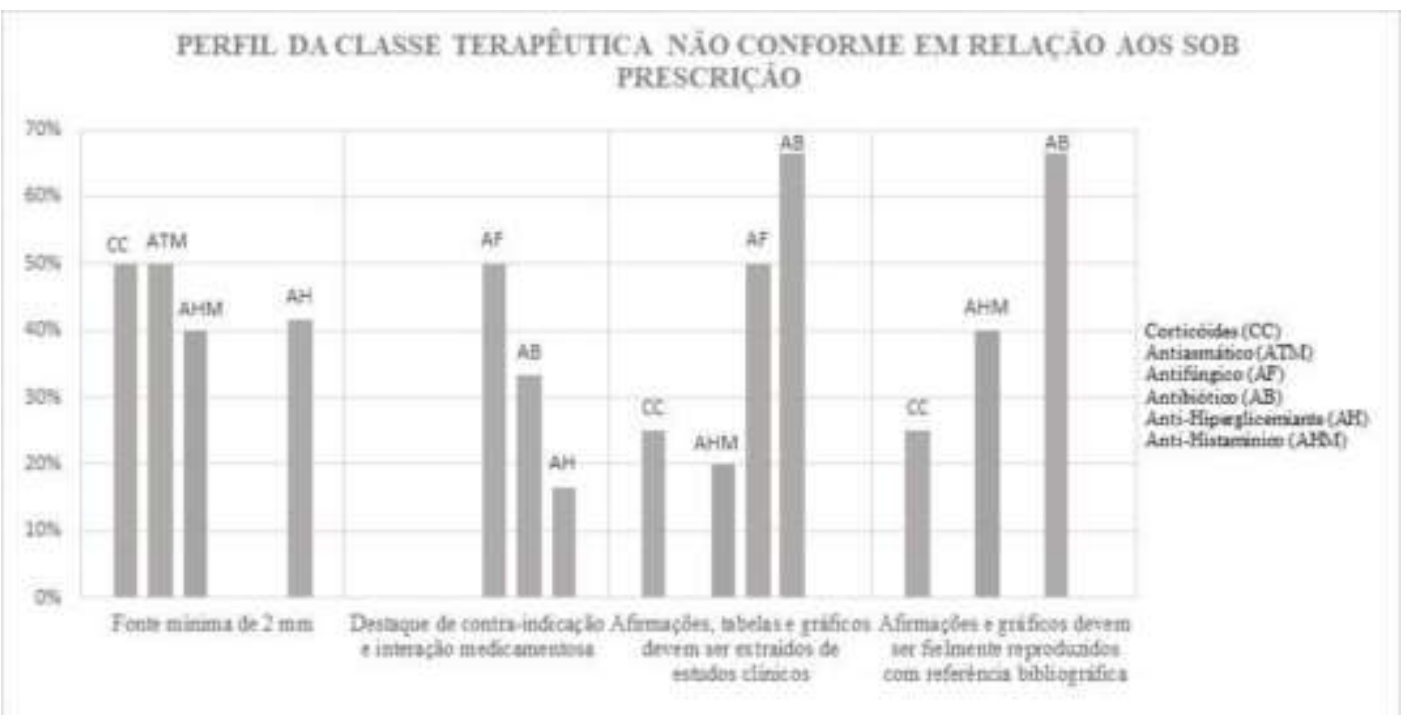

Fonte: Autores.

Fonte menor que $2 \mathrm{~mm}, 50 \%$ dos antiasmáticos e corticóides, 42\% dos anti-hiperglicemiantes e $40 \%$ dos antihistamínicos sendo de difícil visualização para o consumidor. Em primeiro plano visualiza-se os benefícios do medicamento com letras em destaque, enquanto as letras menores são quase que ilegíveis devido ao tamanho reduzido e pouco espaçamento entre elas, segundo Pizzol, Silva \& Schenkel (1998) que tiveram 73\% das peças analisadas no estudo com letras de tamanho menor que o preconizado. Ratificando um padrão regulatório falho, 29\% das peças do estudo realizado por Abdalla and Castillo (2017) apresentavam má legibilidade e baixa visualização de informações obrigatórias (Abdalla \& Castilho, 2017).

Não destacaram uma contraindicação e uma interação medicamentosa, 50\% dos antimicóticos, 33,3\% dos antibióticos e 16,6\% dos anti-hiperglicemiantes. A ausência destes itens, retrata o quanto as informações consideradas "contrapropagandas" como também os riscos, efeitos adversos, advertências e precauções têm sido omitida dos consumidores. Essa irregularidade se perpetua na propaganda, porque camuflar as restrições de uso é uma boa estratégia para que esses medicamentos continuem sendo prescritos. Corroborando, no estudo de Nascimento \& Sayd (2005) é exposto que as contraindicações estavam ausentes em 94 dos 100 anúncios analisados.

Continham afirmações, gráficos ou tabelas que não foram extraídos de estudos clínicos, 66,6\% dos antibióticos, 50\% dos antifúngicos, $25 \%$ dos corticóides e $20 \%$ dos anti-histamínicos.

Identificou-se ainda que as propagandas analisadas não reproduziram afirmações e gráficos com referência bibliográfica, $66,6 \%$ dos antibióticos, $40 \%$ dos anti-histamínicos e $25 \%$ dos corticoides.

A irresponsabilidade da indústria farmacêutica em divulgar, por meio de materiais promocionais, informações não verídicas acerca de seus produtos e veiculá-los a profissionais prescritores têm sido uma ferramenta amplamente utilizada para propagandear de maneira desleal. Trabalhos da área relatam o viés na seleção de estudos, pois são escolhidos apenas aqueles que apresentam benefícios do produto, sendo pagos pela própria indústria. Dessa forma, órgãos responsáveis pelas publicações dos periódicos mostram apreensão com a parcialidade dos ensaios clínicos publicados, a intervenção da indústria nestes e a liberdade dos pesquisadores. O cenário torna-se ainda mais grave ao perceber que este material robusto, muitas vezes denominado 'monografia', disponibilizado aos profissionais é uma fonte de atualização científica responsável por possíveis prescrições incorretas (Abdalla \& Castilho, 2017). 
Nesse cenário, é evidente a importância da fiscalização de propagandas dando devida importância à análise e proveniência dos dados contidos nestas, a fim de proteger a população contra materiais publicitários enganosos e que podem acarretar danos à saúde.

Em relação à análise das classes terapêuticas, destacam-se três das quais obtiveram maior proporção de nãoconformidades: antiácidos, hormônios e antieméticos.

\section{Considerações Finais}

A análise comparativa das legislações RDC 102/2000 (revogada) e RDC 96/2008 (vigente) possibilitou discutir itens imprescindíveis que foram trazidos para a legislação atual e concomitantemente, demonstrando consonância às diretrizes da OMS.

No que se refere à avaliação das peças publicitárias analisadas, é possível observar que apesar da resolução vigente atuar na regulação de propagandas; o monitoramento de tais ainda apresenta fragilidades. As brechas na fiscalização constituem um risco iminente à saúde pública, induzindo profissionais ao erro de prescrição e motivando a automedicação ao privar os consumidores de informações cruciais como, as contraindicações.

Nesse sentido, é evidente a necessidade de um novo modelo regulatório que favoreça o rastreio de irregularidades antes que as propagandas sejam exibidas ao público e ao prescritor. Além disso, a aplicação de multas de valores proporcionais ao ganho da indústria farmacêutica é uma forma direta de coibir a propaganda enganosa. Desta forma, não se trata de coibir a propaganda, mas sim de imputar a indústria e ao comercio de medicamentos a responsabilidade de cumprir os dispositivos legais e atender ao disposto pela Política Nacional de Medicamentos.

Por fim, os resultados obtidos reiteram a importância de monitoramento e programas educativos. Estes devem atuar, prioritariamente, no ambiente da comercialização reforçando a farmacovigilância das informações contidas em rótulos, bulas, peças publicitárias e todo material gráfico disponibilizado e vinculado aos medicamentos. Para que assim, seja diminuído o risco de danos à saúde.

Para desenvolvimento de pesquisa posterior, serão utilizados dados referentes à classe medicamentosa dos AINEs, os quais tiveram notoriedade significativa neste estudo. Estes consistem em notificações de Queixas Técnicas analisadas e classificadas, a fim de fortalecer ações da vigilância sanitária no pós-uso e pós-comercialização destes que oferecem potencial risco à saúde pública.

\section{Referências}

Abdalla M. \& Castilho S. (2017). Análise da propaganda de medicamentos dirigida a profissionais de saúde. R. Dir. Sanit. Ago 2017; 18(1):101-20.

Agência Nacional De Vigilância Sanitária (2017). Regulamentação da Propaganda de Medicamentos: RDC 96 - Perguntas e Respostas, http://www.vigilanciasanitaria.sc.gov.br/index.php/download/category/127-medicamentos?download=980:resolucao-rdc-n-96-2008-regulamentacao-dapropaganda-de-medicamentos

Agência Nacional De Vigilância Sanitária (2000). Resolução de Diretoria Colegiada nº 102, de 30 de novembro de 2000. Regulamento sobre propagandas, mensagens publicitárias e promocionais e outras práticas cujo objeto seja a divulgação, promoção ou comercialização de medicamentos. Diário Oficial da União 1 Dez 2000.

Agência Nacional De Vigilância Sanitária (2008). Resolução da Diretoria Colegiada n 96, de 17 de dezembro de 2008 . Regulamento sobre propagandas, mensagens publicitárias e promocionais e outras práticas cujo objeto seja a divulgação, promoção ou comercialização de medicamentos. Diário Oficial da União 18 Dez 2008.

Andrade S. M, Cunha M. A, Holanda E. C, Coutinho G. S. L, Verde R. M. C. L., \& Oliveira E. H (2020) Caracterização do perfil das intoxicações medicamentosas por automedicação no Brasil, durante o período de 2010 a 2017. Research, Society and Development, 2020; 9(7): 1-16, e236973952.

Araujo C. P, Bochner R \& Nascimento A. C (2012). Marcos legais da propaganda de medicamentos: avanços e retrocessos. Physis, Revista de Saúde Coletiva, 2012; (22): 331-346. 
Barros J. A. C., \& Joany S. (2002) Anúncios de medicamentos em revistas médicas: ajudando a promover a boa prescrição? Ciência \& Saúde Coletiva, 2002; 7(4): 891-898.

Brasil (1976). Lei nº 6.360, de 23 de setembro de 1976. Dispõe sobre a vigilância sanitária. Diário Oficial da União 24 Set 1976 ; Seção 1: 12647.

Brasil (1996). Lei n. 8.078, de 11 de setembro de 1990. Dispõe sobre a proteção do consumidor e dá outras providências. Diário Oficial da União 12 Set 1990; Seção 1: 8 .

Brasil (1996). Decreto Federal n. 2.018 de 01 de outubro de 1996. Regulamenta a Lei no 9.294, de 15 de julho de 1996 , que dispõe sobre as restrições ao uso e à propaganda de produtos fumígenos, bebidas alcoólicas, medicamentos, terapias e defensivos agrícolas, nos termos do $\S 4^{\circ}$ do art. 220 da Constituição. Diário Oficial da União 2 Out 1996; Seção 1: 19707

Brasil (1998). Portaria N³.916, de 30 de Outubro de 1998. Aprova a Política Nacional de Medicamentos. Diário Oficial da União 30 Ou 1998 ; Seção 1: 64.

Brasil (1990). Lei nº.069, de 13 de julho de 1990. Estatuto da Criança e do Adolescente. Diário Oficial da União. 16 Jul 1990.

Brasil (1999). Lei n. 9.782, de 26 de janeiro de 1999. Define o Sistema Nacional de Vigilância Sanitária, cria a Agência Nacional de Vigilância Sanitária, e dá outras providências. <http://www.planalto.gov.br/ccivil_03/leis/L9782.htm>.

Costa A. L. P., \& Silva A. C. S. Jr. (2017) Resistência bacteriana aos antibióticos e Saúde Pública: uma breve revisão de literatura. Macapá, 2017 Mai; 7(2): 4557.

Fagundes M. J. D, Soares M. G. A, \& Diniz N. M (2007). Análise bioética da propaganda e publicidade de medicamentos. Ciência \& Saúde Coletiva, 2007 Jan; 12(1): 221-229.

Feitoza-Silva, M., Fernandes, B., Carvalho, S., Carvalho, C., Vale, R., Nobre, P., Leandro, K., \& Gemal, A. L. Certificação compulsória e qualidade de agulhas e seringas em um Hospital Sentinela. Visa em Debate, maio 2016; 4(2):21-6.

Klein K, Souza N. S, Ribeiro A. C., \& Silva E. B. (2020) Automedicação em crianças de zero a cinco anos: práticas de seus cuidadores/familiares. Research, Society and Development, 2020; 9(7): 1-20, e520974296

Maia S. S, Souza V. S, Souza E. D., \& Faustino T. N (2019). Anos potenciais de vida perdidos por intoxicação exógena no Brasil no período de 2007 a 2017, Rev. Enferm. Contemp, Salvador, Outubro; 8(2):135-142.

Mastroianni P. C, Vaz A. C. R, Noto A. R \& Galduróz J. C. F. (2008) Análise do conteúdo de propagandas de medicamentos psicoativos. Rev. Saúde Pública Out 2008; 42(5): 968-971.

Ministério Da Saúde (2005). Estudo Comparado: Regulamentação da Propaganda de Medicamentos. Monitoração de Propaganda, http://www.ccs.saude.gov.br/visa/publicacoes/arquivos/Estudo_comparado_propaganda.pdf

Nascimento A. C \& Sayd J. D (2005). Ao persistirem os sintomas, o médico deverá ser consultado: isto é regulação? Physis 2005; 15(2):305-328.

Nascimento, A. C. (2007). Propaganda de medicamentos: como conciliar uso racional e a permanente necessidade de expandir mercado? Trab. educ. saúde 2007; 5(2): 189-250.

Organização Mundial De Saúde (1985). Critérios éticos para la promoción de medicamentos. Genebra: Organização Mundial da Saúde. Serie de Informes Téchnicos, 1985; 722: 47.

Pizzol, F. D; Silva, T \& Schenkel, E. P. (1998). Análise da adequação das propagandas de medicamentos dirigidas à categoria médica distribuídas no Sul do Brasil. Cad. Saúde Pública Jan. 1998; 14(1): 85-91.

Pereira A. S, Shitsuka D. M, Parreira F. J \& Shitsuka R. (2018) Metodologia da pesquisa científica. UFSM. https://repositorio.ufsm.br/bitstream/handle/1/15824/Lic_Computacao_Metodologia-Pesquisa-Cientifica.pdf?sequence=1 .

Sato M. K. S (2002). A propaganda e a publicidade de medicamentos e a informação ao consumidor. R. Dir. Sanit. Nov 2002; 3(3): 89-115.

Sistema Nacional de Informações Tóxico-Farmacológicas. Fundação Oswaldo Cruz. Casos registrados de intoxicação humana, 2008. http://www.fiocruz.br/sinitox_novo/media/tab06_brasil_2008.pdf

Sistema Nacional de Informações Tóxico-Farmacológicas (2017). Fundação Oswaldo Cruz. Casos Registrados de Intoxicação Humana por Agente Tóxico e Circunstância. <https://sinitox.icict.fiocruz.br/dados-nacionais>

Silva P, Rangel B \& Castilho S (2018). Avaliação da propaganda de medicamentos isentos de prescrição em farmácias comunitárias do Município de Niterói (RJ, Brasil). R. Dir. Sanit 18(3): 77-3.

Trevisol D. J, Ferreira M. B. C \& Karnopp Z. M. P (2010). A propaganda de medicamentos em escola de medicina no sul do Brasil. Ciência \& Saúde Coletiva 15(3): 3487-3496

Villanueva, P., Peiró, S., Librero, J., \& Pereiró, I. Accuracy of Pharmaceutical Advertisement In Medical Journals. Lancet. $2003 ; 361(9351)$ : 27-32. 